\title{
Article \\ Constitutive Equation for Flow Stress in Superalloy 718 by Inverse Analysis under Hot Forming in a Region of Precipitation
}

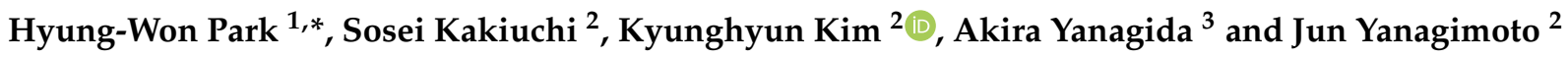 \\ 1 Faculty of Production Systems Engineering and Sciences, Komatsu University, Nu-1-3 Shichōmachi, Komatsu, \\ Ishikawa 923-8511, Japan \\ 2 Department of Mechanical Engineering, The University of Tokyo, Hongo 7-3-1, Bunkyo-ku, \\ Tokyo 113-8656, Japan; evtm37@gmail.com (S.K.); kkhpnu96@gmail.com (K.K.); \\ jun.52074.yanagimoto@cem.t.u-tokyo.ac.jp (J.Y.) \\ 3 Department of Advanced Machinery Engineering, School of Engineering, Tokyo Denki University, \\ 5 Senju-Asahi-cho, Adachi-ku, Tokyo 120-8551, Japan; yanagida@mail.dendai.ac.jp \\ * Correspondence: hyungwon.park@komatsu-u.ac.jp
}

\section{check for} updates

Citation: Park, H.-W.; Kakiuchi, S.; Kim, K.; Yanagida, A.; Yanagimoto, J. Constitutive Equation for Flow Stress in Superalloy 718 by Inverse Analysis under Hot Forming in a Region of Precipitation. Crystals 2021, 11, 811 . https://doi.org/10.3390/ cryst 11070811

Academic Editors:

Nobufumi Ueshima, Jovana Ruzic, Hongzhi Cui and Ikumu Watanabe

Received: 30 May 2021

Accepted: 4 July 2021

Published: 12 July 2021

Publisher's Note: MDPI stays neutral with regard to jurisdictional claims in published maps and institutional affiliations.

Copyright: (c) 2021 by the authors. Licensee MDPI, Basel, Switzerland. This article is an open access article distributed under the terms and conditions of the Creative Commons Attribution (CC BY) license (https:// creativecommons.org/licenses/by/ $4.0 /)$.

\begin{abstract}
The purpose of this study is to obtain a constitutive equation of high-accuracy flow stress in superalloy 718, which allows fabrication of highly reliable disks for gas turbine engines. Hot compression tests using superalloy 718 at deformation temperatures from 850 to $1100{ }^{\circ} \mathrm{C}$, a $67 \%$ height reduction, and strain rates of 1,10 , and $25 \mathrm{~s}^{-1}$ were performed to investigate the flow stress behavior, which excludes environmental effects during hot working by inverse analysis. The effects of dynamic recrystallization and strain-induced dynamic precipitation on the flow stress were also investigated. The dynamically precipitated $\delta$ phases deformed at $1050{ }^{\circ} \mathrm{C}$ and $\gamma^{\prime \prime}$ phases deformed at $950^{\circ} \mathrm{C}$ might affect the increase in the plastic modulus $F_{1}$ and the decrease in the critical strain $\varepsilon_{c}$, deteriorating the accuracy of regression in terms of, for example, the strain rate sensitivity $m$ and the temperature sensitivity $A$. A constitutive equation for a generalized flow curve for superalloy 718 is proposed by considering these effects.
\end{abstract}

Keywords: nickel-based superalloy; flow stress; constitutive equation; dynamic precipitation; hot working

\section{Introduction}

As an aircraft engine component, gas turbine disks with a gear shape are exposed to temperatures up to $650{ }^{\circ} \mathrm{C}$ at the outer periphery, a high rotation speed of about 10,500 rpm, and a load of more than $1000 \mathrm{MPa}$ at the inner periphery at takeoff. Therefore, the disks should have high performance characteristics such as tensile strength at elevated temperatures, creep properties, low-cycle fatigue, and crack propagation resistance [1]. To satisfy these critical characteristics, the hot forging and heat treatment in Ni-based superalloys such as superalloy 718 have been applied in manufacturing gas turbine disks [2-4]. In the manufacture of large parts using an ultralarge forging press machine, the process prediction using computer-aided engineering (CAE) is applied to estimate the deformation behavior of a material during load, temperature, and microstructural evolution with mechanical properties [5], because there are not only cost problems such as the use of expensive materials and molds, but also a precise forging process at elevated temperatures is required to obtain heat-resistant products through microstructural control. Thus, a high-accuracy formulation of flow stress is critical for predicting the high-precision forging load by CAE, which consists of functions of stress, strain, strain rate, and temperature. Various experiments have been carried out to obtain the constitutive equation of flow stress in Ni-based superalloys at elevated temperatures and various strain rates [6-10]. However, experimental results may include the effects of internal-external heat transfer, friction, and 
heat generated by deformation during hot working, leading to heterogeneous deformation. The effects should be compensated prior to determining the flow stress by inverse analysis (IA) coupled with thermomechanical CAE [11,12]. To achieve a uniaxial flow stress, for which these affects are compensated, a variety of studies have been carried out by this approach using $\mathrm{Cr}-\mathrm{Mo}-\mathrm{V}[13]$, carbon [14,15] and stainless [16,17] steels, an aluminum alloy [18,19], and a nickel-based superalloy [20].

By referring to the precipitation-temperature-time (PTT) diagram for superalloy 718 [21], we can infer that gamma double prime $\left(\gamma^{\prime \prime}\right)$, gamma single prime $\left(\gamma^{\prime}\right)$, and delta ( $\delta)$ phases can be precipitated in the temperature range from about 700 to $1050{ }^{\circ} \mathrm{C}$. Generally, the microsized $\delta$ phase in block and needle shapes precipitate mainly at grain boundaries, suppressing grain growth at elevated temperatures [22,23]. Nanosized $\gamma^{\prime \prime}$ phases with an elongated disk shape and $\gamma^{\prime}$ phases with a spheroidal shape precipitate primarily in grains, increasing the strength of the material [24,25]. Hence, a solid-solution treatment at about $950{ }^{\circ} \mathrm{C}$ for $1 \mathrm{~h}$ and a two-step aging treatment at about $720{ }^{\circ} \mathrm{C}$ for $8 \mathrm{~h}$ for the first step and about $620^{\circ} \mathrm{C}$ for $10 \mathrm{~h}$ for the second step was performed to precipitate both $\gamma^{\prime \prime}$ and $\gamma^{\prime}$ phases in the matrix [4]. Strain-induced dynamic precipitation (SIDP) may occur, when the strain is applied to precipitate hardenable metals during hot working under specific conditions [26-28]. Precipitation strengthening or softening is induced by dynamic precipitation under working condition and then dynamic precipitation changes the flow stress during hot working [28-31]. Accordingly, it is essential to investigate the effects of SIDP on flow stress in superalloy 718 in the temperature range from about 700 to $1050{ }^{\circ} \mathrm{C}$. Dynamic recrystallized ultrafine grains in superalloy 718 were formed with high strength after compression at temperatures from 900 to $1050{ }^{\circ} \mathrm{C}$ and strain rates from 0.001 to $10 \mathrm{~s}^{-1}$ [9]. Furthermore, most of the studies on the flow stress have been carried out at strain rates lower than $10 \mathrm{~s}^{-1}[6-9,27]$. However, to contribute to productivity improvement, it is important to investigate the flow stress behavior at strain rates higher than $10 \mathrm{~s}^{-1}$.

The purpose of this study is to obtain a constitutive equation of the high-accuracy flow stress in superalloy 718, which allows fabrication of highly reliable disks of gas turbine engines. Hot compression tests using superalloy 718 at deformation temperatures from 850 to $1100{ }^{\circ} \mathrm{C}$, a $67 \%$ height reduction, and strain rates of 1,10 , and $25 \mathrm{~s}^{-1}$ were performed to investigate the flow stress behavior including dynamic recrystallization (DRX) and SIDP. The constitutive equation of this behavior was obtained.

\section{Materials and Methods}

\subsection{Materials}

In this study, superalloy 718 was subjected to a solid-solution treatment for $2 \mathrm{~h}$ at $1070{ }^{\circ} \mathrm{C}$, which is higher than the delta solvus, to dissolve $\delta$ phases into the matrix. It was then machined into specimens of two sizes, $8 \mathrm{~mm}$ diameter $\times 12 \mathrm{~mm}$ height and $6 \mathrm{~mm}$ diameter $\times 9 \mathrm{~mm}$ height, for hot compression tests. The microstructure of the solid-solution-treated superalloy 718 with an average grain size of approximately $21 \mu \mathrm{m}$ showed equiaxed grains with twins; a few microsized $\delta$ phases remained around the grain boundary, as shown in Figure 1. Its chemical composition is shown in Table 1.

Table 1. Chemical composition of superalloy 718 (mass\%).

\begin{tabular}{cccccccccccc}
\hline $\mathbf{N i}$ & $\mathbf{C r}$ & $\mathbf{N b}$ & $\mathbf{T i}$ & $\mathbf{A l}$ & $\mathbf{C o}$ & $\mathbf{M n}$ & $\mathbf{C u}$ & $\mathbf{C}$ & $\mathbf{S i}$ & $\mathbf{B}$ & $\mathbf{F e}$ \\
\hline 52.4 & 18.4 & 5.37 & 0.99 & 0.60 & 0.24 & 0.06 & 0.06 & 0.03 & 0.06 & 0.004 & Bal. \\
\hline
\end{tabular}



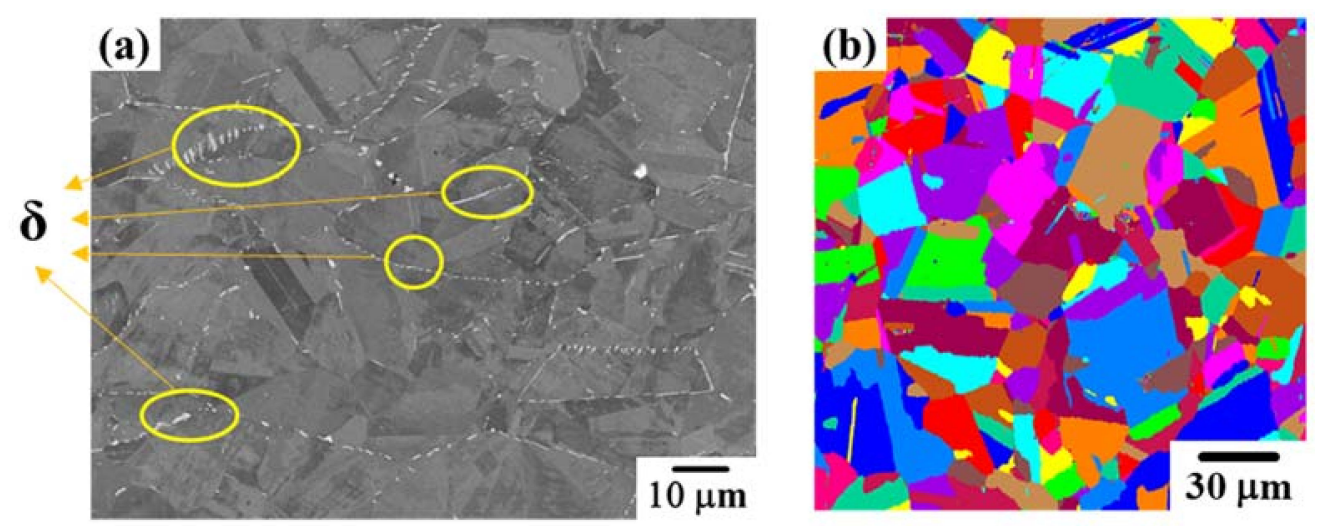

Figure 1. Microstructure of solid-solution-treated superalloy 718 with an average grain size of approximately $21 \mu \mathrm{m}$ : (a) FE-SEM image and (b) unique grain map $\left(\theta<15^{\circ}\right)$.

\subsection{Hot Compression Tests and Microstructural Observation}

Fifteen ton and five ton high-speed compression-testing machines (ThermecMastorZ, Fuji Electronic Industrial Co., Ltd., Tsurugashima, Japan) were used in this test. Hot compression tests were performed to obtain load-stroke data at deformation temperatures from 850 to $1100{ }^{\circ} \mathrm{C}$, a $67 \%$ height reduction (an average strain of 1.1), and strain rates of 1,10 , and $25 \mathrm{~s}^{-1}$. The 15-ton compression-testing machine was used at deformation temperatures from 900 to $1100{ }^{\circ} \mathrm{C}$ using a specimen of $8 \mathrm{~mm}$ diameter $\times 12 \mathrm{~mm}$ height. The 5-ton compression-testing machine was used only at a deformation temperature of $850^{\circ} \mathrm{C}$ using a specimen of $6 \mathrm{~mm}$ diameter $\times 9 \mathrm{~mm}$ height.

Mica sheets were placed between the dies and the specimen to reduce both the friction and heat transfer to the dies. Nitrogen gas was used as an inert atmosphere to prevent the oxidation of the specimen at elevated temperatures. The specimen was induction-heated at a constant rate of $10^{\circ} \mathrm{C} \mathrm{s}^{-1}$ up to the target temperature and then held at this temperature for $3 \mathrm{~min}$ to homogenize the temperature distribution. Afterward, the specimen was compressed to $67 \%$ height reduction and then water-quenched to freeze the microstructure. The compression test profile of temperature vs. time is shown in Figure 2.

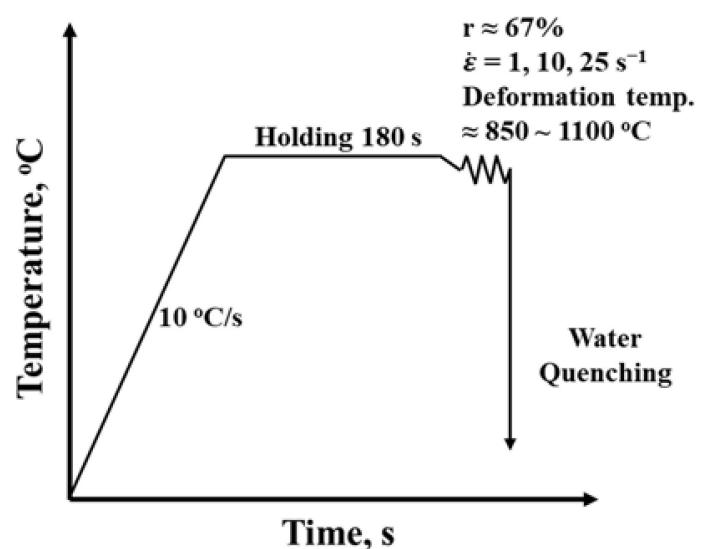

Figure 2. Compression test profile of temperature vs. time.

To investigate the microstructures of the test specimens, the specimens were cut in half along their compression axis before and after the hot compression tests. The cut specimens were mechanically polished with abrasive paper and $0.04 \mu \mathrm{m}$ OP-U nondrying colloidal silica suspension. They were then characterized by field-emission scanning electron microscopy (FE-SEM, JEOL 7100F) electron backscattering diffraction (EBSD) analysis. 


\subsection{Flow Curve Determination by Inverse Analysis Coupled with Thermomechanical CAE}

The constitutive equation for the flow curve used in IA was proposed by Yanagida et al. [11], where the softening phenomena such as dynamic recovery (DRV) and DRX during deformation were taken into account. The equation is expressed as

$$
\begin{gathered}
\left\{\begin{array}{c}
\bar{\sigma}=F_{1} \bar{\varepsilon}^{n} \quad\left(\bar{\varepsilon} \leq \varepsilon_{c}\right) \\
\bar{\sigma}=F_{2} \exp \left[a\left(\bar{\varepsilon}-\varepsilon_{\max }\right)^{2}\right]+F_{3} \quad\left(\bar{\varepsilon} \geq \varepsilon_{\mathcal{c}}\right)
\end{array},\right. \\
F_{2}=\frac{F_{1} \varepsilon_{\mathcal{c}}{ }^{n}-F_{3}}{\exp \left[a\left(\varepsilon_{\mathcal{c}}-\varepsilon_{\max }\right)^{2}\right]}, \\
a=\frac{n F_{1} \varepsilon_{\mathrm{c}}{ }^{n-1}}{2\left(\varepsilon_{\mathrm{c}}-\varepsilon_{\max }\right)\left(F_{1} \varepsilon_{\mathrm{c}}{ }^{n}-F_{3}\right)}, \\
\varepsilon_{\max }=\varepsilon_{\mathrm{c}}+\frac{F_{1} \varepsilon_{\mathrm{c}}{ }^{n}-F_{3}}{n F_{1} \varepsilon_{\mathrm{c}}{ }^{n-1}-(n-1) \varepsilon_{\mathrm{c}}{ }^{-1}\left(F_{1} \varepsilon_{\mathrm{c}}{ }^{n}-F_{3}\right)}, \\
\sigma_{f}=\bar{\sigma} \cdot \dot{\varepsilon}^{m_{0}},
\end{gathered}
$$

where $F_{1}$ (plastic modulus), $n$ (work hardening exponent), $\varepsilon_{c}$ (critical strain), $\varepsilon_{\max }$ (strain at peak stress), and $F_{3}$ (steady-state stress) are independent parameters that can be obtained by IA, and all are material constants with clear individual physical meanings. Moreover, $F_{2}, a$, and $\varepsilon_{\max }$ are dependent parameters when full dynamic recrystallization occurs during deformation and continuity of the stress condition and its first- and second-order derivatives at $\varepsilon_{c}$ are applied.

The distributed internal temperature used in IA is calculated as

$$
\begin{aligned}
\rho c\left(\frac{\partial T}{\partial t}-v_{r} \frac{\partial T}{\partial r}\right) & =\frac{\kappa}{r}\left(r \frac{\partial^{2} T}{\partial r^{2}}-\frac{\partial^{2} T}{\partial z}\right)+\dot{Q}, \\
\dot{Q} & =\sigma_{f} \dot{\varepsilon}+\dot{q}_{e}
\end{aligned}
$$

where $\rho, c, \kappa$, and $\dot{Q}$ are the density, specific heat, thermal conductivity, and amount of internal heat generated, respectively; $\sigma_{f} \dot{\varepsilon}$ is the amount of internal heat generated by plastic work, and $\dot{q}_{e}$ is the amount of internal heat generated by the electromagnetic factor of induction heating. As can be seen from Equation (7), a high flow stress and a high strain rate can lead to greater internal heat generation.

The flow stress $\bar{\sigma}$ in Equation (1) is obtained below, taking $T_{0}$ as the reference temperature corresponding to the initial testing temperature:

$$
\left.\bar{\sigma}\right|_{T}=\left.\bar{\sigma}\right|_{T_{0}} \frac{\exp \left(A_{0} / T\right)}{\exp \left(A_{0} / T_{0}\right)}
$$

By using $\left.\bar{\sigma}\right|_{T}$ in Equation (8) instead of $\bar{\sigma}$ in Equation (5), we obtain the flow curve with a compensated temperature and strain rate distribution inside the workpiece by IA, expressed as

$$
\left.\bar{\sigma}^{*}\right|_{T}=\left.\bar{\sigma}\right|_{T} \cdot \cdot^{m_{0}},
$$

where $m_{0}$ is the strain rate sensitivity at reference temperature $T_{0}$. From Equation (9), $\left.\bar{\sigma}^{*}\right|_{T}$ represents the temperature-corrected flow stress and $\left.\bar{\sigma}\right|_{T_{0}}$ is the stress at the reference temperature [11]. Therefore, the stress decreases at a specific point with increasing temperature. The stress was obtained before IA to determine the flow curve from the load-stroke curve of hot compression test by dividing the measured load by the cross section assuming a uniform deformation, which is here called the apparent stress. In this work, $m_{0}=0.08$ (strain rate sensitivity) and two $A_{0}$ values (temperature sensitivity), $A_{0}=7000$ or 8000 , are selectively applied to reduce the remaining error in IA and to improve the accuracy of flow stress expressed by Equation (1). As a result of the parameter regression shown later in the 
results and discussion, there is no marked difference between this assumed value and the final one obtained, so it is considered that the change in the flow curve is small even when $m_{0}$ and $A_{0}$ are updated and regression is again performed.

The flow stress was determined by IA associated with thermomechanical-electromagnetic coupled finite element analysis (FEA), using an in-house code [12], to minimize the error between the measured load-reduction curves and the independent parameters of the flow curve determined in Equation (1). The IA performed to identify the flow curve was terminated when the error between the measured load and the calculated load became lower than the threshold determined using the least squares method (Lavenberg-Marquardt method). The final relative error in calculated loads in IA of hot compression test and experiments, which is an identification error of upsetting force in IA, lies in the 1-2.5\% range, which is denoted as "error" in the rightmost column in Table 2.

Table 2. Parameters for flow stress determined by inverse analysis.

\begin{tabular}{|c|c|c|c|c|c|c|c|}
\hline Temperature, ${ }^{\circ} \mathrm{C}$ & Strain Rate, $\mathrm{s}^{-1}$ & $F_{1}$ & $n$ & $\varepsilon_{\mathrm{c}}$ & $F_{3}$ & $\varepsilon_{\max }$ & Error, $\%$ \\
\hline \multirow{3}{*}{1100} & 1 & 255.248 & 0.030 & 0.123 & 196.800 & 0.231 & 1.8 \\
\hline & 10 & 336.008 & 0.111 & 0.217 & 199.017 & 0.388 & 2.0 \\
\hline & 25 & 420.233 & 0.158 & 0.232 & 226.308 & 0.406 & 2.2 \\
\hline \multirow{3}{*}{1050} & 1 & 320.102 & 0.036 & 0.119 & 250.717 & 0.219 & 0.7 \\
\hline & 10 & 425.052 & 0.090 & 0.190 & 287.614 & 0.332 & 1.5 \\
\hline & 25 & 532.354 & 0.178 & 0.258 & 302.749 & 0.434 & 1.9 \\
\hline \multirow{3}{*}{1000} & 1 & 361.269 & 0.046 & 0.163 & 265.924 & 0.301 & 1.8 \\
\hline & 10 & 512.820 & 0.126 & 0.248 & 308.279 & 0.436 & 1.9 \\
\hline & 25 & 605.083 & 0.205 & 0.337 & 357.156 & 0.551 & 1.9 \\
\hline \multirow{3}{*}{950} & 1 & 549.412 & 0.072 & 0.119 & 507.551 & 8.267 & 2.1 \\
\hline & 10 & 640.235 & 0.134 & 0.302 & 376.275 & 0.533 & 2.4 \\
\hline & 25 & 728.158 & 0.251 & 0.369 & 372.241 & 0.619 & 1.5 \\
\hline \multirow{3}{*}{900} & 1 & 695.208 & 0.124 & 0.832 & 721.084 & 0.086 & 2.2 \\
\hline & 10 & 836.635 & 0.257 & 0.448 & 585.873 & 0.620 & 1.9 \\
\hline & 25 & 873.508 & 0.343 & 0.489 & 512.182 & 0.730 & 1.6 \\
\hline \multirow{3}{*}{850} & 1 & 990.674 & 0.214 & 0.312 & 976.117 & -14.271 & 1.4 \\
\hline & 10 & 1098.662 & 0.247 & 0.736 & 908.623 & 0.976 & 2.2 \\
\hline & 25 & 1210.014 & 0.361 & 0.704 & 983.583 & 0.835 & 2.2 \\
\hline
\end{tabular}

\section{Results and Discussion}

\subsection{Comparison of Flow Curves Obtained by Experiment and Inverse Analysis}

Figure 3 shows flow curves obtained by experiment (dotted line) and IA (line) at deformation temperatures from 850 to $1100{ }^{\circ} \mathrm{C}$ and strain rates of 1,10 , and $25 \mathrm{~s}^{-1}$. The flow curves obtained by experiment are calculated using Equation (10) and IA results are summarized in Table 2, which are used to calculate the flow stress:

$$
\left\{\begin{array}{c}
\sigma=\frac{F}{A} \cdot \frac{L_{0}-\Delta L}{L_{0}} \\
\varepsilon=-\ln \left(\frac{L_{0}-\Delta L}{L_{0}}\right)
\end{array},\right.
$$

where $L_{0}$ and $A$ are the original height and area of the specimen before compression, and $F$ and $\Delta L$ are the load and stroke during compression, respectively. 
(a)

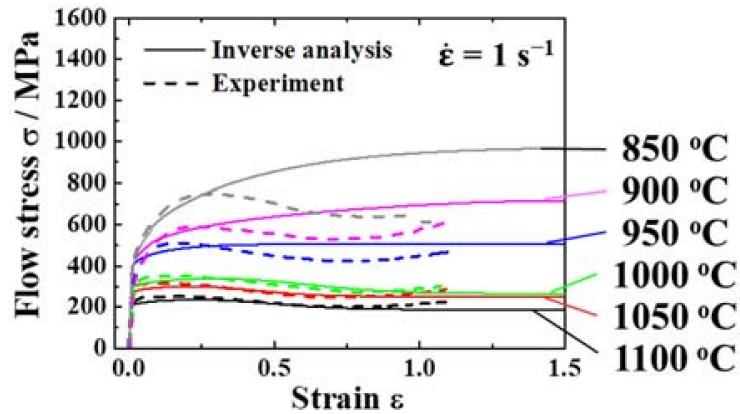

(b)

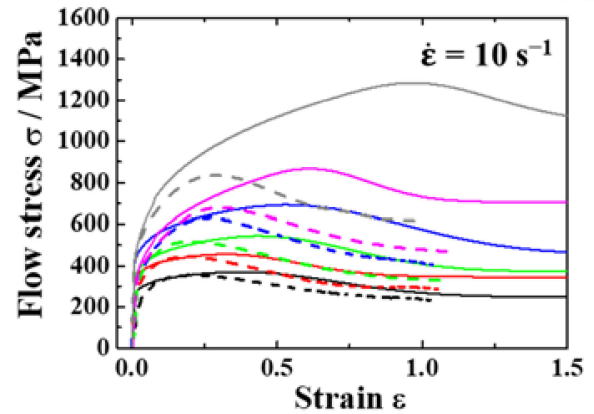

(c)

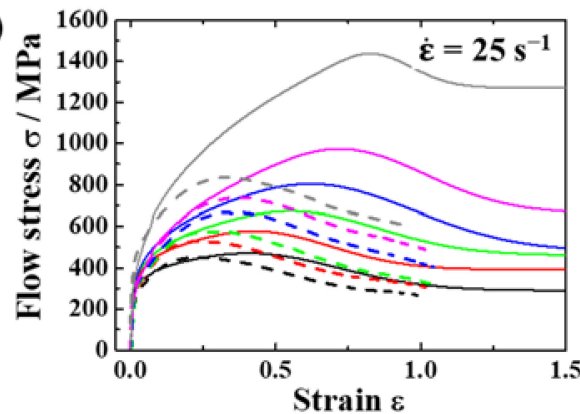

Figure 3. Flow curves obtained from experiment (dotted line) and inverse analysis (line) at deformation temperatures from 850 to $1100{ }^{\circ} \mathrm{C}$ and strain rates of (a) 1 , (b) 10 , and (c) $25 \mathrm{~s}^{-1}$.

As shown in Figure 3, with decreasing deformation temperature and increasing strain rate, both flow stresses obtained by experiment and IA increase. At a strain rate of $1 \mathrm{~s}^{-1}$, as shown in Figure 3a, the experimental axial flow stresses at deformation temperatures from 850 to $1100{ }^{\circ} \mathrm{C}$ represent the DRX behavior. On the other hand, the flow stresses obtained by IA show work hardening (WH) behavior at deformation temperatures of 850 and $900{ }^{\circ} \mathrm{C}$ and complex dynamic events such as WH and DRV or WH, DRV, and DRX at a deformation temperature of $950{ }^{\circ} \mathrm{C}$. At strain rates from 1 to $25 \mathrm{~s}^{-1}$, a small difference between both flow curves obtained by experiment and IA is observed at deformation temperatures above $1000{ }^{\circ} \mathrm{C}$ and strain rates below $10 \mathrm{~s}^{-1}$. However, the larger difference between the curves can be observed at deformation temperatures below $1000{ }^{\circ} \mathrm{C}$ and strain rates above $10 \mathrm{~s}^{-1}$. The significant differences clearly show that an unrealistic stress-strain curve will be obtained by the hot compression test and indicated by Equation (10), due to severe heterogeneous deformation, heat generated by deformation during hot working, internal-external heat transfer and induced temperature distribution inside test piece, and friction. This homogeneity may lead to low stress obtained by experiments, compared to uniaxial-flow stress at uniform temperature and strain rate identified by the IA of load-stroke curve in the experiment.

The calculated temperature distribution (1/4 axisymmetric model) of superalloy 718 compressed at a $60 \%$ height reduction, various strain rates, and deformation temperatures of 950 and $1100{ }^{\circ} \mathrm{C}$ is visualized using micro $\mathrm{AVS}^{\circledR}$ and shown in Figure 4. The figure shows that the temperature is higher at the center of the specimen and lower near the top surface. At a strain rate of $1 \mathrm{~s}^{-1}$ and both deformation temperatures, the temperature near the center surface (right side) is higher owing to the electromagnetic factor of induction heating rather than the heat generated by the plastic work. The temperature difference $(\Delta T)$ values between the maximum and deformation temperatures at strain rates of 1,10 , and $25 \mathrm{~s}^{-1}$ are 18,95 , and $120^{\circ} \mathrm{C}$ at a deformation temperature of $950{ }^{\circ} \mathrm{C}$, and the differences are 2,60 , and $81{ }^{\circ} \mathrm{C}$ at a deformation temperature of $1100{ }^{\circ} \mathrm{C}$, respectively. $\Delta T$ increases with increasing strain rate and decreasing deformation temperature, meaning that the heat generated by the plastic work is higher. 


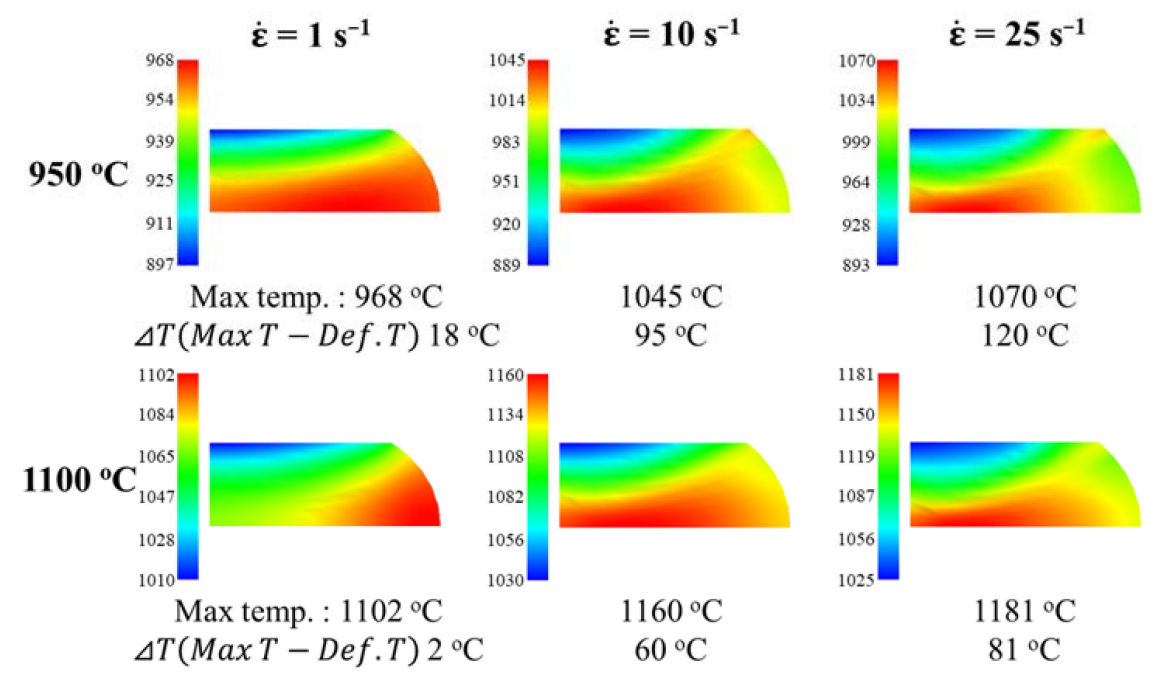

Figure 4. Temperature distribution (1/4 axisymmetric model) at deformation temperatures of 950 and $1100{ }^{\circ} \mathrm{C}$, a $60 \%$ height reduction, and strain rates of 1,10 , and $25 \mathrm{~s}^{-1}$.

The $\Delta T$ in $0.2 \%$ carbon steel compressed at a $75 \%$ height reduction, a strain rate of $200 \mathrm{~s}^{-1}$, and a deformation temperature of $1000{ }^{\circ} \mathrm{C}$ was $61^{\circ} \mathrm{C}$ [15]. In contrast, the $\Delta T$ in superalloy 718 compressed at a $60 \%$ height reduction, a strain rate of $25 \mathrm{~s}^{-1}$, and a deformation temperature of $1100{ }^{\circ} \mathrm{C}$ was $81^{\circ} \mathrm{C}$. Despite the small height reduction, low strain rate, and high deformation temperature, the heat generated by the plastic work in superalloy 718 is larger than that in $0.2 \%$ carbon steel.

Figure 5 shows the microstructural evolution of superalloy 718 , where the center of the specimen in the middle of the compression axis was observed, compressed at a $67 \%$ height reduction, deformation temperatures of 950 and $1100{ }^{\circ} \mathrm{C}$, and strain rates of 1,10 , and $25 \mathrm{~s}^{-1}$. Nonrecrystallized areas and ultrafine microstructures with an average grain size from 1 to $3 \mu \mathrm{m}$ at a deformation temperature of $950^{\circ} \mathrm{C}$ were widely observed, as shown in Figure $5 \mathrm{a}-\mathrm{c}$. In contrast, almost fully recrystallized areas and fine microstructures with an average grain size from 6 to $9 \mu \mathrm{m}$ at a deformation temperature of $1100{ }^{\circ} \mathrm{C}$ were observed, as shown in Figure $5 \mathrm{~d}-\mathrm{f}$. With increasing strain rate and deformation temperature, the grain size and DRX fraction tend to increase.
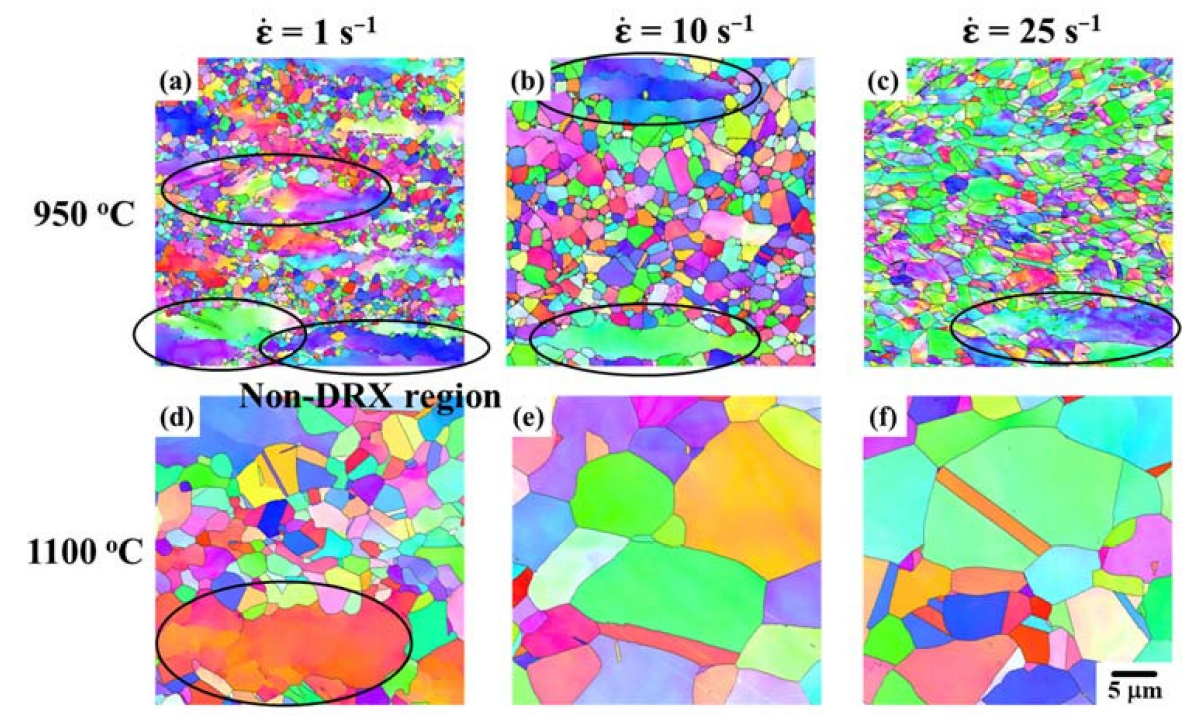

Figure 5. Microstructural evolution of superalloy 718 compressed at $67 \%$ height reduction, deformation temperatures of $(\mathbf{a}-\mathbf{c}) 950^{\circ} \mathrm{C}$ and $(\mathbf{d}-\mathbf{f}) 1100^{\circ} \mathrm{C}$, and strain rates of $(\mathbf{a}, \mathbf{d}) 1 \mathrm{~s}^{-1},(\mathbf{b}, \mathbf{e}) 10 \mathrm{~s}^{-1}$, and $(\mathbf{c}, \mathbf{f}) 25 \mathrm{~s}^{-1}$. 
The flow curve obtained from the experimental results at a deformation temperature of $950{ }^{\circ} \mathrm{C}$ and a strain rate of $1 \mathrm{~s}^{-1}$ shows strong DRX behavior. On the other hand, the flow curve obtained from IA results at a deformation temperature of $950{ }^{\circ} \mathrm{C}$ and a strain rate of $1 \mathrm{~s}^{-1}$ shows complex dynamic events such as WH and DRV or WH, DRV, and DRX, as shown in Figure 3a. As noted, the experimental results used to obtain the flow curve may include the effects of internal-external heat transfer, friction, and heat generated owing to deformation during hot working, leading to the heterogeneous deformation, so that uniaxial flow stress rather than axial flow stress can be achieved. Accordingly, it seems reasonable to conclude that flow curves obtained by IA show the original flow behavior, which is the uniaxial flow curve.

\subsection{Flow Curve Regression}

The logarithmic relationship between the maximum stress (peak stress) of flow curves using the hyperbolic sine-law equation and the Zener-Hollomon parameter $(Z)$ [32] is used to validate the results of IA:

$$
Z=\dot{\bar{\varepsilon}} \exp \left(\frac{Q_{D R X}}{R T}\right)=A^{\prime}[\sinh (\alpha \bar{\sigma})]^{n^{\prime}},
$$

where $\dot{\bar{\varepsilon}}$ is the strain rate $\left(\mathrm{s}^{-1}\right), Q_{D R X}$ is the activation energy for DRX $(\mathrm{J} / \mathrm{mol}), R$ is the gas constant $(8.314 \mathrm{~J} / \mathrm{mol} \mathrm{K}), T$ is the deformation temperature $(\mathrm{K}), \bar{\sigma}$ is the flow stress $(\mathrm{MPa})$, and $A^{\prime}, \alpha$, and $n^{\prime}$ are material constants. A good validity of IA results is shown in Figure 6.

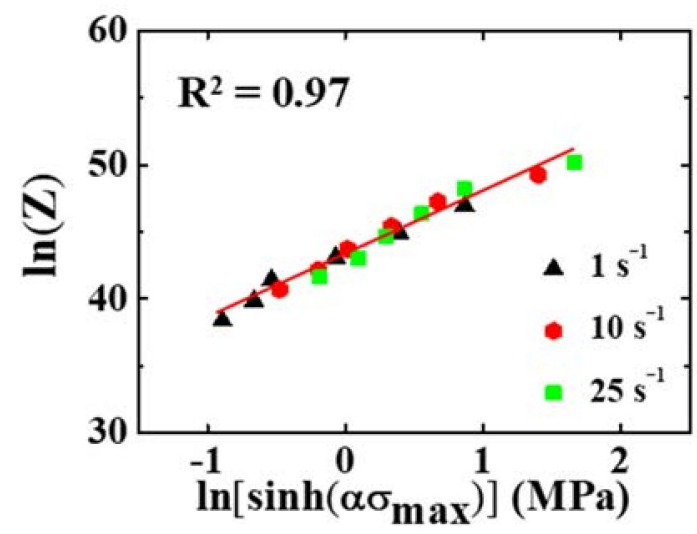

Figure 6. Hyperbolic sine function of flow stresses obtained from inverse analysis according to the Zener-Holloman parameter.

The DRX activation energy of this alloy at deformation temperatures from 850 to $1100{ }^{\circ} \mathrm{C}$ and strain rates from 1 to $25 \mathrm{~s}^{-1}$ was calculated to be $438.17 \mathrm{~kJ} / \mathrm{mol}$. Azarbarmas et al. [7] reported that the hot deformation activation energy of superalloy 718 at deformation temperatures from 950 to $1100{ }^{\circ} \mathrm{C}$ and strain rates from 0.001 to $10 \mathrm{~s}^{-1}$ was $437 \mathrm{~kJ} / \mathrm{mol}$, which was calculated using the hyperbolic sine-law equation. Hot deformation activation energies of $429-467 \mathrm{~kJ} / \mathrm{mol}$ in superalloy 718 have also been reported $[33,34]$; these activation energies are similar to those we obtained in this investigation. In addition, Nowotnik [28] reported that the mean hot deformation activation energy in superalloy 718 compressed at a strain rate of about $10^{-4} \mathrm{~s}^{-1}$ and temperatures from 900 to $1150{ }^{\circ} \mathrm{C}$ was $450.8 \mathrm{~kJ} / \mathrm{mol}$ and that it increased from 354 to $590 \mathrm{~kJ} / \mathrm{mol}$ with decreasing deformation temperature from 1150 to $900{ }^{\circ} \mathrm{C}$.

The relationships among the critical strain $\varepsilon_{\mathcal{C}}$, the work hardening coefficient $n$, and the $\mathrm{Z}$ parameter are shown in Figure 7 , and $\varepsilon_{c}$ and $n$ were calculated as

$$
\begin{gathered}
\mathcal{E}_{\mathcal{C}}=B_{1} Z^{B_{2},} \\
n=B_{3} \ln Z+B_{4},
\end{gathered}
$$


where $B_{1}$ is $0.00027, B_{2}$ is $0.1569, B_{3}$ is 0.0274 , and $B_{4}$ is $-1.0414 ; \varepsilon_{\mathcal{c}}$ and $n$ for non-DRX regions at deformation temperatures of 850 and $900{ }^{\circ} \mathrm{C}$, and a strain rate of $1 \mathrm{~s}^{-1}$ were excluded to obtain a regression to reduce error.

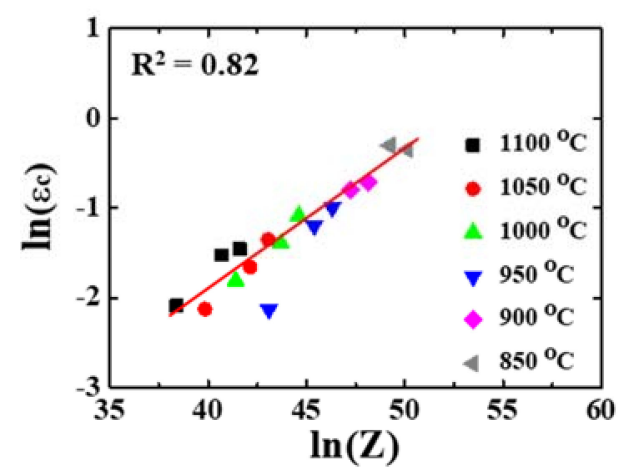

(a)

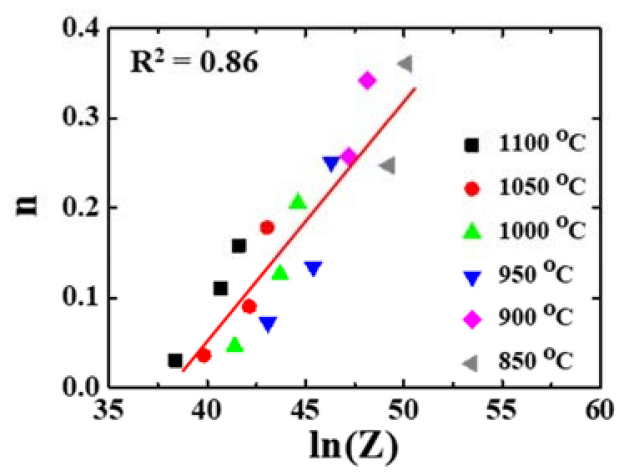

(b)

Figure 7. (a) Critical strain $\varepsilon_{c}$ and (b) work hardening coefficient $n$ according to Zener-Holloman parameter.

The strain rate sensitivity $m$ depends on the deformation temperature, as shown in Figure 8, and is expressed by Equation (14) as

$$
m=4.32 \times 10^{-4} \mathrm{~T}-0.4276,
$$

where $T$ is the deformation temperature $(\mathrm{K})$.

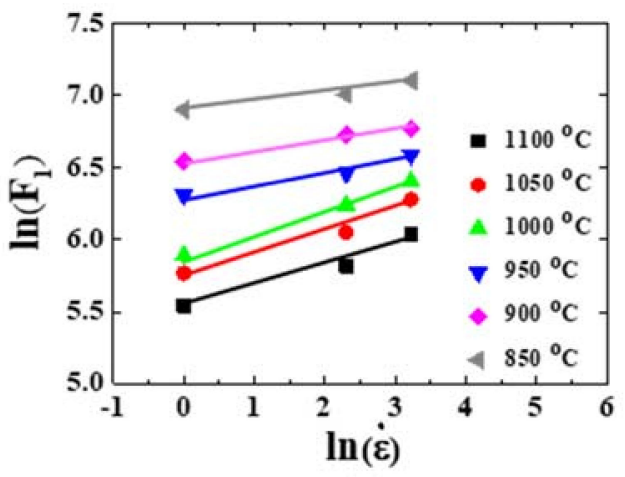

(a)

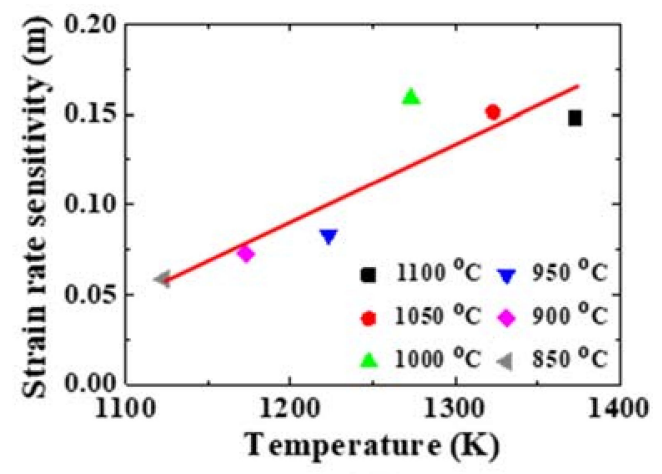

(b)

Figure 8. Strain rate sensitivity $m$ at various temperatures calculated as (a) $m=\partial \ln \left(F_{1}\right) / \partial \ln (\dot{\varepsilon})$ and (b) the regression of the strain rate sensitivity $m$ as a function of temperature.

In Figure $8 \mathrm{a}$, the plastic modulus $F_{1}$ tends to a relatively significant increase with decreasing deformation temperature from 1100 to $1050{ }^{\circ} \mathrm{C}$ and from 1000 to $950{ }^{\circ} \mathrm{C}$, diminishing the accuracy of the regression for the strain rate sensitivity, as shown in Figure 8b.

The arithmetic average of the work hardening coefficient $\bar{n}$ was used instead of the scattered $n$ values to calculate the optimized plastic modulus $F_{1}{ }^{*}$ [12]. The plastic modulus $F_{1}$ is modified to $F_{1}{ }^{\prime}$ using

$$
\begin{gathered}
\int_{0}^{\mathcal{E}_{c}} F_{1} \bar{\varepsilon}^{n} d \bar{\varepsilon}=\int_{0}^{\mathcal{E}_{\mathcal{c}}} F_{1}{ }^{\prime} \bar{\varepsilon}^{\bar{n}} d \bar{\varepsilon} \\
F_{1}^{\prime}=\frac{(\bar{n}+1) F_{1} \varepsilon_{c}^{n}}{(n+1) \varepsilon_{c}^{\bar{n}}} .
\end{gathered}
$$


The optimized plastic modulus $F_{1}{ }^{*}$ and the optimized steady-state stress $F_{3}{ }^{*}$ depend on the temperature. Accordingly, $F_{1}{ }^{*}$, and $F_{3}{ }^{*}$ can be expressed as

$$
\begin{gathered}
\ln \left(F_{1}{ }^{\prime} \dot{\varepsilon}^{\left(m_{0}-m\right)}\right)=A\left(\frac{1}{T}-\frac{1}{T^{*}}\right)+\ln \left(F_{1}{ }^{*}\right) \\
\ln \left(F_{3}\right)=A\left(\frac{1}{T}-\frac{1}{T^{*}}\right)+\ln \left(F_{3}{ }^{*}\right),
\end{gathered}
$$

where $A$ is the temperature sensitivity and $T^{*}$ is the reference temperature.

Figure 9 shows regressions of the temperature sensitivity $A$ regressed by $\ln \left(F_{1}{ }^{\prime} \dot{\varepsilon}^{m_{0}-m}\right)$ and $\ln \left(F_{3}\right)$ as functions of $10^{3}\left(1 / T-1 / T^{*}\right) ; 1223 \mathrm{~K}\left(950{ }^{\circ} \mathrm{C}\right)$ was used as the reference temperature $T^{*}$. The temperature sensitivity $A 1$ and the optimized plastic modulus $F_{1}^{*}$ are 5301.8 and 536.8, and the temperature sensitivity $A 2$ and the optimized steady-state stress $F_{3}{ }^{*}$ are 9108.2 and 336.8 , respectively. The values of $\ln \left(F_{1}{ }^{\prime} \dot{\varepsilon}^{m_{0}-m}\right)$ at deformation temperatures of 950 and $1050{ }^{\circ} \mathrm{C}$ are located above the regression line of $\ln \left(F_{1}{ }^{\prime} \dot{\varepsilon}^{m_{0}-m}\right)$ as a function of $10^{3}\left(1 / T-1 / T^{*}\right)$, as shown in Figure 9 a. In particular, the value at a deformation temperature of $950{ }^{\circ} \mathrm{C}$ deviates further from the regression line. This is attributed to the fact that $F_{1}{ }^{\prime} \dot{\varepsilon}^{\left(m_{0}-m\right)}$ at deformation temperatures of 950 and $1050{ }^{\circ} \mathrm{C}$ increases at relatively high $F_{1}$ and low $\varepsilon_{c}$ values.

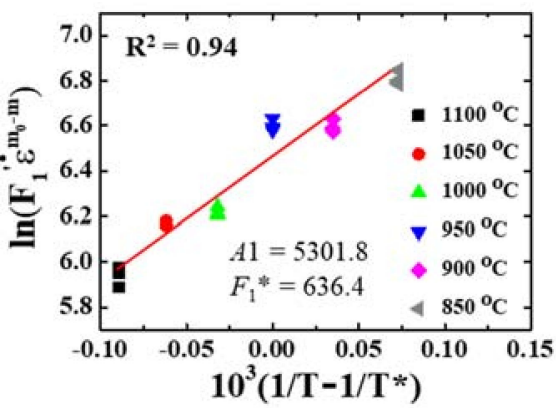

(a)

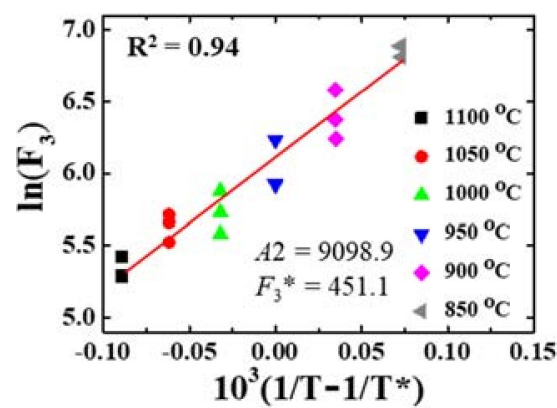

(b)

Figure 9. Temperature sensitivity $A$ and each optimized stress regressed by (a) $\ln \left(F_{1}^{\prime} \dot{\varepsilon}^{m_{0}-m}\right)$ and (b) $\ln \left(F_{3}\right)$ as functions of $10^{3}\left(1 / T-1 / T^{*}\right)$ with reference temperature $T^{*}=1223 \mathrm{~K}\left(950{ }^{\circ} \mathrm{C}\right)$.

\subsection{Generalized Flow Curve}

The complete formulation of the generalized flow curve can be expressed as

$$
\sigma^{*}=\bar{\sigma}^{m} \exp \left[A\left(\frac{1}{T}-\frac{1}{T^{*}}\right)\right]\left\{\begin{array}{c}
\bar{\sigma}=F_{1}^{*} \bar{\varepsilon}^{n} \\
\bar{\sigma}=F_{2}{ }^{*} \exp \left[a^{*}\left(\bar{\varepsilon}-\varepsilon_{\max }\right)^{2}\right]+F_{3}^{*}\left(\bar{\varepsilon} \geq \varepsilon_{c}\right)
\end{array}\right\}
$$

where $m$ is the strain rate sensitivity, $n$ is the work hardening coefficient, and $\varepsilon_{\mathcal{c}}$ is the critical strain. The optimized plastic modulus $F_{1}{ }^{*}$ and the optimized steady-state stress $F_{3}{ }^{*}$ are constant values, $A$ is the temperature sensitivity obtained by regression, $T^{*}$ is the reference temperature $(\mathrm{K})$, and $F_{2}{ }^{*}$ and $a^{*}$ are dependent coefficients. The parameters used to obtain generalized flow curve are summarized in Table 3. 
Table 3. Parameters used to obtain the generalized flow curve.

\begin{tabular}{cc}
\hline Parameters & Values or Equations \\
\hline Strain rate sensitivity $m$ & $4.32 \times 10^{-4} T-0.4276$ \\
\hline Temperature sensitivity $A$ & $\begin{array}{c}A 1=5301.8 \text { (comparison) } \\
A 2=9108.2 \text { (applied) }\end{array}$ \\
\hline Work hardening coefficient $n$ & $2.74 \times 10^{-2}\left\{\dot{\varepsilon} \exp \left(\frac{52,703}{T}\right)\right\}-1.0414$ \\
\hline Critical strain $\varepsilon_{\mathcal{C}}$ & $2.67 \times 10^{-4}\left\{\dot{\varepsilon} \exp \left(\frac{52,703}{T}\right)\right\}^{0.1569}$ \\
\hline Optimized plastic modulus $F_{1}^{*}$ & 636.4 \\
\hline Optimized steady-state stress $F_{3}^{*}$ & 451.1 \\
\hline Reference temperature $T^{*}(\mathrm{~K})$ & 1223 \\
\hline
\end{tabular}

Figure 10 shows the flow curves obtained from results of IA and the constitutive equation (CE) calculated using temperature sensitivities $A 1$ and $A 2$. In the case of using $A 1$ to calculate $\mathrm{CE}$, flow curves obtained from IA and $\mathrm{CE}$ results at various deformation temperatures and strain rates show inferior matching; however, when $A 2$ is applied, high matching of flow curves obtained from IA and CE results can be shown. Since the formulation of the generalized flow curve is based on the dynamic softening of DRV and DRX, the flow curves obtained from IA and CE results at deformation temperatures of 900 and $850{ }^{\circ} \mathrm{C}$ and a strain rate of $1 \mathrm{~s}^{-1}$ show worse matching, where the flow curve obtained from results of $\mathrm{CE}$ calculation shows the DRX behavior, whereas the flow curve obtained from IA results shows WH behavior.
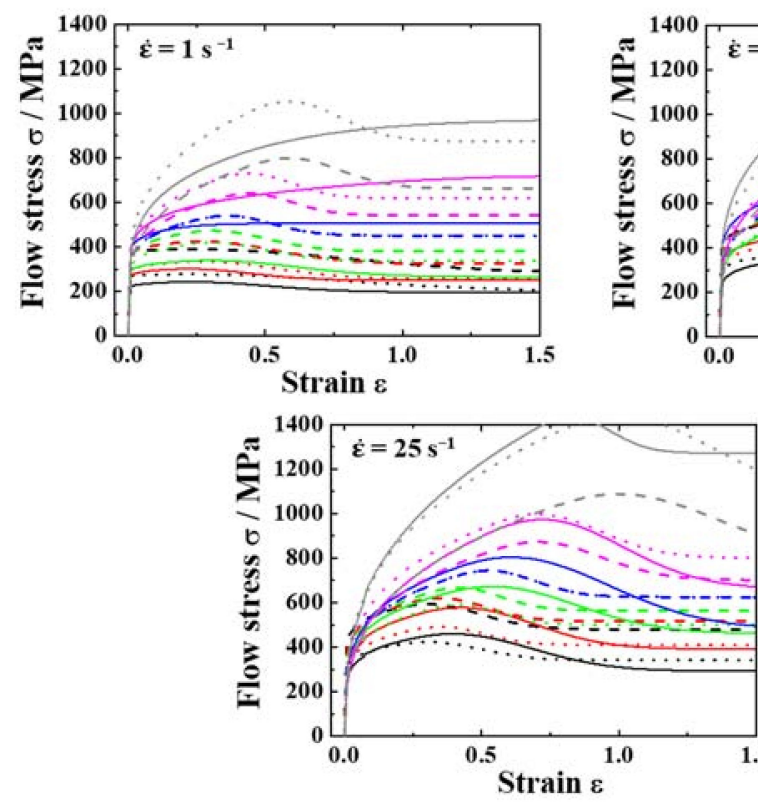

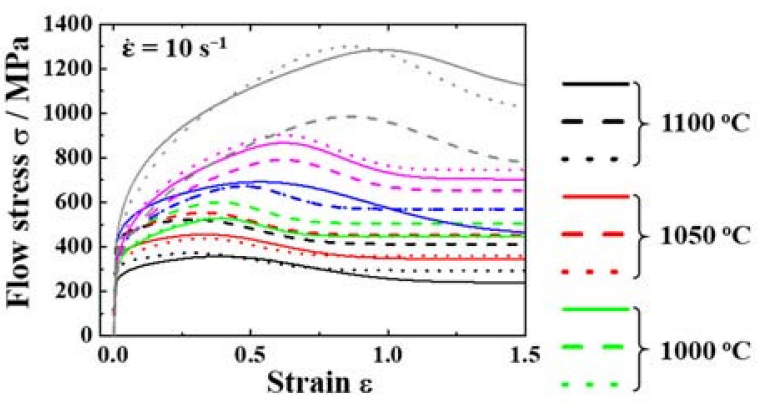

- Inverse analysis

- - Constitutive equation (A1) ... Constitutive equation (A2)

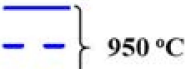

$--\} 950^{\circ} \mathrm{C}$

$--\} 900^{\circ} \mathrm{C}$

$\ldots$

$--\} 850^{\circ} \mathrm{C}$

Figure 10. Flow curves obtained from results of IA and CEs calculated using temperature sensitivities $A 1$ and $A 2$.

To compare the flow stress correlation between IA and CEs calculated using $A 1$ and $A 2$ ( $\mathrm{CE}(A 1)$ and $\mathrm{CE}(A 2)$, respectively), the relationship of the peak flow stress and the steady-state stress at $\varepsilon_{2.0}$ between IA and CE is shown in Figure 11 . The $45^{\circ}$ line on the $x-y$ axis is the reference axis, and the error decreases as it converges to the reference axis. The relative error $\xi$ can be expressed as

$$
\xi=\frac{1}{N} \sum\left|\frac{\sigma_{\mathrm{CE}}-\sigma_{\mathrm{IA}}}{\sigma_{\mathrm{IA}}}\right| \times 100 \% .
$$




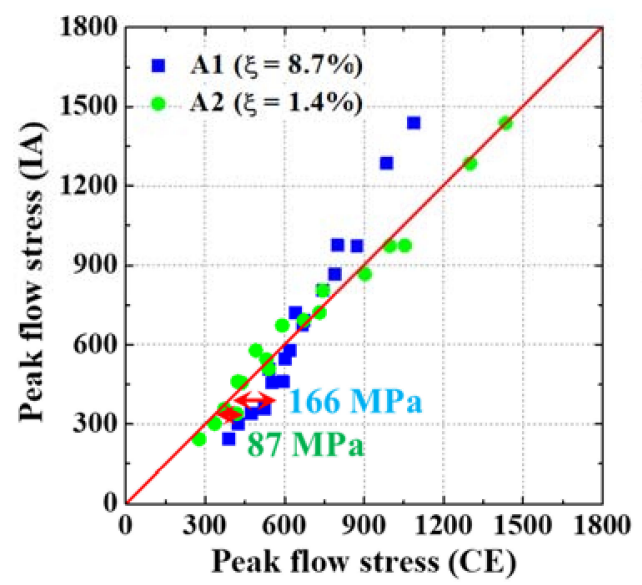

(a)

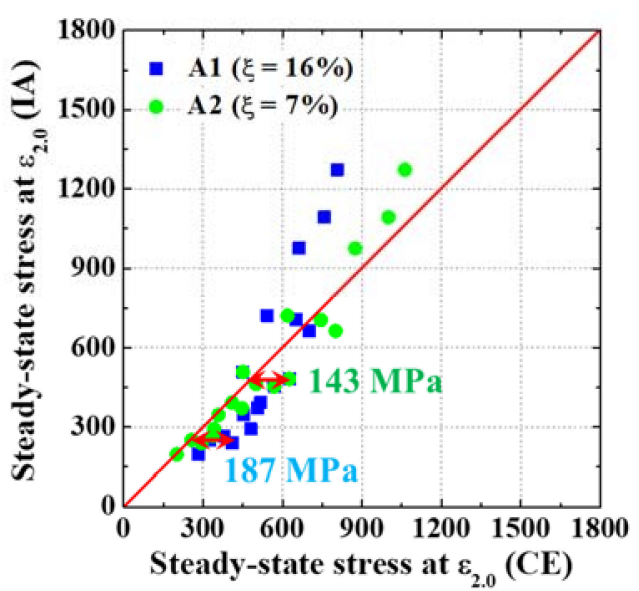

(b)

Figure 11. Flow stress correlation between IA and CEs calculated using temperature sensitivities $A 1$ and $A 2$ : (a) peak flow stress and (b) steady-state stress at $\varepsilon_{2.0}$.

In the relationship for the peak flow stress shown in Figure 11a, except for two values for non-DRX regions at deformation temperatures of 850 and $900{ }^{\circ} \mathrm{C}$, and a strain rate of $1 \mathrm{~s}^{-1}$, the maximum difference between IA and CE $(A 1)$ is $166 \mathrm{MPa}$. In contrast, that between IA and $\mathrm{CE}(A 2)$ is $87 \mathrm{MPa}$. Under all conditions, the relative error $\xi$ between IA and $\mathrm{CE}(A 1)$ is $8.7 \%$; however, relative error between IA and $\mathrm{CE}(A 2)$ is $1.4 \%$. In the relationship for the steady-state stress at $\varepsilon_{2.0}$ shown in Figure $11 \mathrm{~b}$, except for the two values mentioned above, the maximum differences between IA and $\mathrm{CE}(A 1)$, and between IA and $\mathrm{CE}(A 2)$ are 187 and $143 \mathrm{MPa}$, respectively. Under all conditions, the relative error $\xi$ values between IA and $\mathrm{CE}(A 1)$, and between IA and $\mathrm{CE}(A 2)$ are $16 \%$ and $7 \%$, respectively. In the case of $\mathrm{CE}(A 2)$, a higher correlation of the peak flow stress and the steady-state stress between IA and $\mathrm{CE}$ can be confirmed.

By referring to the PTT diagram [21], we can infer that the $\delta$ and the $\gamma^{\prime \prime}$ phases can be precipitated by holding the temperature at around 950 and $850{ }^{\circ} \mathrm{C}$ for about $10 \mathrm{~min}$, respectively. Thomas et al. [21] mentioned that the PTT curve moves towards higher temperatures when the precipitation in superalloy 718 occurs concurrently with deformation. When superalloy 718 was compressed at deformation temperatures from 800 to $950{ }^{\circ} \mathrm{C}$, a strain rate of $0.1 \mathrm{~s}^{-1}$, and strains up to 0.2 , the start time of precipitation in the PTT diagram decreases slightly with increasing applied deformation [26]. In 26 NiCrMoV 14-5 medium carbon low alloy steel compressed at $950{ }^{\circ} \mathrm{C}$ and higher, and at low strain rates $\left(0.01-0.1 \mathrm{~s}^{-1}\right)$, DRX precedes dynamic precipitation and decreases considerably the work hardening rate; however, at very high strain rates $\left(1 \mathrm{~s}^{-1}\right.$ and higher), dynamic precipitation is stimulated and precedes DRX; therefore, the flow curve is characterized by a high value [31]. The occurrence of precipitation is a function of solid-solution concentration, strain, temperature, and time. Accordingly, it can be considered that the PTT curve can move in any direction depending on the abovementioned condition. In this study, SIDP during hot working might be activated because of the relatively higher strain rate from 1 to $25 \mathrm{~s}^{-1}$, shifting the PTT curve to the northwest side, which corresponded to both shorter times and higher temperatures. Similarly, the strain-induced dynamic transformation (SIDT) occurs during hot working [35-37].

After precipitation in the matrix, dislocations are accumulated around precipitates during deformation, resulting in an increase in stress caused by the generated stress zone near precipitates [38]. The precipitation strengthening due to coherency strains is expressed by

$$
\Delta \sigma \approx 6 G \varepsilon^{3 / 2} \sqrt{\frac{r f}{b}}
$$

where $G$ is the shear modulus, $\varepsilon$ is the measure of the strain field, $r$ is the radius of a precipitate particle, $f$ is the volume fraction of the dispersed phase, and $b$ is the Burgers vector. 
The stress required to force the dislocation between precipitates is expressed by

$$
\tau=\frac{G b}{\lambda}
$$

where $\lambda$ is the length between precipitates.

These equations mean that the stress increases with increasing $\varepsilon, r$, and $f$, and decreasing $\lambda$. In the observation area, that is, the center of a specimen compressed at $950{ }^{\circ} \mathrm{C}$ and a strain rate of $25 \mathrm{~s}^{-1}$, the nanosized $\gamma^{\prime \prime}$ phases with circular and elongated disk shapes, and the microsized $\delta$ phases with block shapes can be observed throughout the microstructure, as shown in Figure 12. Since the $\gamma^{\prime \prime}$ phases are the main reinforcing factor coherent with the matrix [24], and the $\delta$ phases precipitate at grain boundaries $[39,40]$ and contribute not to precipitation hardening but to grain boundary strengthening [41], the increase in the plastic modulus $F_{1}$ at $950{ }^{\circ} \mathrm{C}$ may be greater than that at $1050{ }^{\circ} \mathrm{C}$. In addition, an unstable state is formed around the precipitates such as the $\gamma^{\prime \prime}$ phases owing to piled-up dislocations caused by deformation and DRX or SIDT occurs as it functions as a nucleation site based on this energy [42-44], decreasing $\varepsilon_{\mathcal{c}}$. Therefore, the dynamically precipitated $\delta$ phases deformed at $1050{ }^{\circ} \mathrm{C}$ and $\gamma^{\prime \prime}$ phases deformed at $950{ }^{\circ} \mathrm{C}$ might affect the increase in $F_{1}$ and the decrease in $\varepsilon_{c}$, reducing the accuracy of regression in terms of, for example, the strain rate sensitivity $m$ and the temperature sensitivity $A 1$. Further research would be necessary to obtain a more accurate generalized flow curve by considering these effects. A schematic illustration of the change of the PTT diagram during hot working at high strain rates is represented in Figure 13.

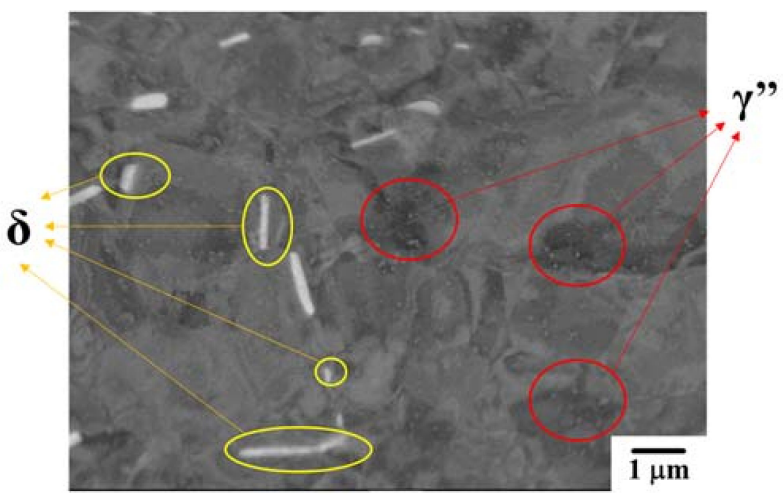

Figure 12. Microstructure with precipitated $\delta$ and $\gamma^{\prime \prime}$ phases in superalloy 718 after hot compression at a $67 \%$ height reduction, a deformation temperature of $950{ }^{\circ} \mathrm{C}$, and a strain rate of $25 \mathrm{~s}^{-1}$.

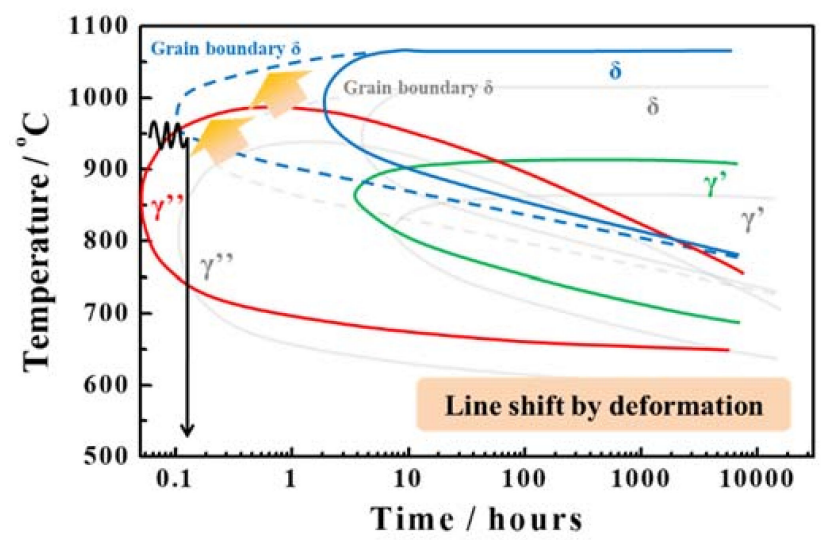

Figure 13. Schematic illustration of shift of PTT diagram during hot working at deformation temperature of $950{ }^{\circ} \mathrm{C}$ and high strain rates. 


\section{Conclusions}

Hot compression tests in superalloy 718 with IA at deformation temperatures from 850 to $1100{ }^{\circ} \mathrm{C}$, a $67 \%$ height reduction, and strain rates of 1,10 , and $25 \mathrm{~s}^{-1}$ were performed to obtain the uniaxial flow stress and its generalized equation considering the effects of DRX and SIDP. The main research results are summarized as follows:

1. A flow curve obtained from experimental results at a deformation temperature of $950{ }^{\circ} \mathrm{C}$ and a strain rate of $1 \mathrm{~s}^{-1}$ shows strong DRX behavior. On the other hand, a flow curve obtained from IA results at a deformation temperature of $950{ }^{\circ} \mathrm{C}$ and a strain rate of $1 \mathrm{~s}^{-1}$ shows weak DRX behavior and complex dynamic events such as DRV and DRX. This might be attributed to the flow curve obtained from the experimental results, including the effects of internal-external heat transfer, friction, and heat generated by hot working, leading to heterogeneous deformation. From IA results, a uniaxial flow stress can be attained to remove those effects.

2. The dynamically precipitated $\delta$ phases deformed at $1050^{\circ} \mathrm{C}$ and $\gamma^{\prime \prime}$ phases deformed at $950^{\circ} \mathrm{C}$ might affect the increase in the plastic modulus $F_{1}$ and the decrease in the critical strain $\varepsilon_{c}$, deteriorating the accuracy of regression in terms of, for example, the strain rate sensitivity $m$ and the temperature sensitivity $A$.

3. A high-precision constitutive equation for the generalized flow curve in superalloy 718 has been achieved by using the temperature sensitivity $A 2$ obtained from the relationship between $\ln \left(F_{3}\right)$ and $10^{3}\left(1 / T-1 / T^{*}\right)$, instead of the temperature sensitivity $A 1$ obtained from the relationship between $\ln \left(F_{1}{ }^{\prime} \dot{\varepsilon}^{m_{0}-m}\right)$ and $10^{3}\left(1 / T-1 / T^{*}\right)$, which is affected by the plastic modulus $F_{1}$ and the critical strain $\varepsilon_{c}$.

Author Contributions: Investigation, H.-W.P. and S.K.; inverse analysis, H.-W.P. and K.K.; methodology, H.-W.P., S.K., K.K., A.Y. and J.Y.; writing—original draft, H.-W.P.; writing—review and editing, K.K., A.Y. and J.Y.; supervision, J.Y. All authors have read and agreed to the published version of the manuscript.

Funding: This work was supported by the Council for Science, Technology and Innovation (CSTI), Cross-ministerial Strategic Innovation Promotion Program (SIP) in Japan, "Structural Materials for Innovation" (Unit No. B21, Development of Innovative Forging Process Technology and Construction of Material/Process Database with the Largescale and Precise Forging Simulator).

Institutional Review Board Statement: Not applicable.

Informed Consent Statement: Not applicable.

Data Availability Statement: The data presented in this study are available on request from the corresponding author.

Conflicts of Interest: The authors declare no conflict of interest.

\section{References}

1. The Japan Research and Development Center for Metals. JRCM NEWS, March 2007; 2-6. Available online: http:/ /www.jrcm.or. jp/jrcmnews/0703jn245.pdf(accessed on 5 July 2021).

2. Thamboo, S.V.; Schwant, R.C.; Yang, L.; Jackman, L.A.; Bond, B.J.; Kennedy, R.L. Large diameter 718 ingots for land-based gas turbines. In Superalloys 718, 625, 706 and Various Derivatives; Loria, E.A., Ed.; TMS: Warrendale, PA, USA, 2001 ; pp. 57-70.

3. Uginet, J.F.; Jackson, J.J. Alloy 718 forging development for large land-based gas turbine. In Superalloys 718, 625, 706 and Derivatives; Loria, E.A., Ed.; TMS: Warrendale, PA, USA, 2005; pp. 57-67.

4. Chamanfar, A.; Sarrat, L.; Jahazi, M.; Asadi, M.; Weck, A.; Koul, A.K. Microstructural characteristics of forged and heat treated Inconel-718 disks. Mater. Des. 2013, 52, 791-800. [CrossRef]

5. Alabort, E.; Reed, R.C.; Barba, D. Combined modelling and miniaturised characterisation of high-temperature forging in a nickel-based superalloy. Mater. Des. 2018, 160, 683-697. [CrossRef]

6. Tan, Y.B.; Ma, Y.H.; Zhao, F. Hot deformation behavior and constitutive modeling of fine grained Inconel 718 superalloy. J. Alloys Compd. 2017, 716, 65-72. [CrossRef]

7. Azarbarmas, M.; Aghaie-Khafri, M.; Cabrera, J.M.; Calvo, J. Microstructural evolution and constitutive equations of Inconel 718 alloy under quasi-static and quasi-dynamic conditions. Mater. Des. 2016, 94, 28-38. [CrossRef] 
8. Chen, F.; Liu, J.; Ou, H.; Lu, B.; Cui, Z.; Long, H. Flow characteristics and intrinsic workability of IN718 superalloy. Mater. Sci. Eng. A 2015, 642, 279-287. [CrossRef]

9. Gujrati, R.; Gupta, C.; Jha, J.S.; Mishra, S.; Alankar, A. Understanding activation energy of dynamic recrystallization in Inconel 718. Mater. Sci. Eng. A 2019, 744, 638-651. [CrossRef]

10. Tang, X.; Wang, B.; Huo, Y.; Ma, W.; Zhou, J.; Ji, H.; Fu, X. Unified modeling of flow behavior and microstructure evolution in hot forming of a Ni-based superalloy. Mater. Sci. Eng. A 2016, 662, 54-64. [CrossRef]

11. Yanagida, A.; Liu, J.; Yanagimoto, J. Flow curve determination for metal under dynamic recrystallization using inverse analysis. Mater. Trans. 2003, 44, 2303-2310. [CrossRef]

12. Yanagida, A.; Yanagimoto, J. Regression method of determining generalized description of flow curve of steel under dynamic recrystallization. ISIJ Int. 2005, 45, 858-866. [CrossRef]

13. Soltanpour, M.; Yanagimoto, J. Material data for the kinetics of microstructure evolution of Cr-Mo-V steel in hot forming. J. Mater. Proc. Technol. 2012, 212, 417-426. [CrossRef]

14. Meng, Y.; Lin, J.Y.; Yanagida, A.; Yanagimoto, J. Modeling static and dynamic kinetics of microstructural evolution in hot deformation of Fe-0.15C-0.2Si-1.4Mn-0.03Nb alloy. Steel Res. Int. 2017, 88, 1700036. [CrossRef]

15. Park, H.W.; Kim, K.; Park, H.W.; Ding, S.; Yanagimoto, J. Formulation of a generalized flow curve for $0.2 \%$ carbon steel under high-speed hot forming conditions by a regression method. ISIJ Int. 2020, 60, 2896-2904. [CrossRef]

16. Dupin, E.; Yanagida, A.; Yanagimoto, J. Modeling static and dynamic kinetics of microstructure evolution in type 316 stainless steel. Steel Res. Int. 2014, 85, 1099-1108. [CrossRef]

17. Kim, K.; Park, H.W.; Ding, S.; Park, H.W.; Yanagimoto, J. Flow stress of duplex stainless steel by inverse analysis with dynamic recovery and recrystallization model. ISIJ Int. 2021, 61, 280-291. [CrossRef]

18. Ding, S.; Khan, S.A.; Yanagimoto, J. Constitutive descriptions and microstructure evolution of extruded A5083 aluminum alloy during hot compression. Mater. Sci. Eng. A 2018, 728, 133-143. [CrossRef]

19. Ding, S.; Khan, S.A.; Yanagimoto, J. Flow behavior and dynamic recrystallization mechanism of A5083 aluminum alloys with different initial microstructures during hot compression. Mater. Sci. Eng. A 2020, 787, 139522. [CrossRef]

20. Horikoshi, S.; Yanagida, A.; Yanagimoto, J. Uniform hot compression of nickel-based superalloy $720 \mathrm{Li}$ under isothermal and low friction conditions. ISIJ Int. 2020, 60, 2905-2916. [CrossRef]

21. Thomas, A.; El-Wahabi, M.; Cabrera, J.M.; Prado, J.M. High temperature deformation of Inconel 718. J. Mater. Proc. Technol. 2006, 177, 469-472. [CrossRef]

22. Desvallees, Y.; Bouzidi, M.; Bois, F.; Beaude, N. Delta phase in INCONEL 718: Mechanical properties and forging process requirements. In Superalloys 718, 625, 706 and Various Derivatives; Loria, E.A., Ed.; TMS: Warrendale, PA, USA, $1994 ;$ pp. $281-291$.

23. Azadian, S.; Wei, L.Y.; Warren, R. Delta phase precipitation in Inconel 718. Mater. Charact. 2004, 53, 7-16. [CrossRef]

24. Slama, C.; Abdellaoui, M. Structural characterization of the aged Inconel 718. J. Alloys Compd. 2000, 306, 277-284. [CrossRef]

25. Kulawik, K.; Buffat, P.A.; Kruk, A.; Wusatowska-Sarnek, A.M.; Czyrska-Filemonowicz, A. Imaging and characterization of $\gamma^{\prime}$ and $\gamma^{\prime \prime}$ nanoparticles in Inconel 718 by EDX elemental mapping and FIB-SEM tomography. Mater. Charact. 2015, 100, 74-80. [CrossRef]

26. Calvo, J.; Penalva, M.; Cabrera, J.M. Characterization of strain-induced precipitation in Inconel 718 superalloy. J. Mater. Eng. Perform. 2016, 25, 3409-3417. [CrossRef]

27. Nowotnik, A.; Sieniawski, J.; Mrówka-Nowotnik, G. Identification of dynamically precipitated phases in hot-working Inconel 718 alloy. J. Achiev. Mater. Manuf. Eng. 2008, 31, 275-280.

28. Nowotnik, A. The influence of hot-deformation parameters on the mechanical properties and precipitation process in nickel based superalloy. In Superalloys 2008; Reed, R.C., Green, K.A., Caron, P., Gabb, T.P., Fahrmann, M.G., Huron, E.S., Woodard, S.A., Eds.; TMS: Warrendale, PA, USA, 2008; pp. 709-718.

29. Chen, S.; Chen, K.; Peng, G.; Chen, X.; Ceng, Q. Effect of heat treatment on hot deformation behavior and microstructure evolution of 7085 aluminum alloy. J. Alloys Compd. 2012, 537, 338-345. [CrossRef]

30. Ebrahimi, G.R.; Momeni, A.; Kazemi, S.; Alinejad, H. Flow curves, dynamic recrystallization and precipitation in a medium carbon low alloy steel. Vacuum 2017, 142, 135-145. [CrossRef]

31. Mirzaee, M.; Keshmiri, H.; Ebrahimi, G.R.; Momeni, A. Dynamic recrystallization and precipitation in low carbon low alloy steel 26NiCrMoV 14-5. Mater. Sci. Eng. A 2012, 551, 25-31. [CrossRef]

32. Sellars, C.M.; McTegart, W.J. On the mechanism of hot deformation. Acta Metall. 1966, 14, 1136-1138. [CrossRef]

33. Cheng, L.; Xue, X.; Tang, B.; Liu, D.; Li, J.; Kou, H.; Li, J. Deformation behavior of hot-rolled IN718 superalloy under plane strain compression at elevated temperature. Mater. Sci. Eng. A 2014, 606, 24-30. [CrossRef]

34. Wang, Y.; Shao, W.Z.; Zhen, L.; Zhang, B.Y. Hot deformation behavior of delta-processed superalloy 718. Mater. Sci. Eng. A 2011, 528, 3218-3227. [CrossRef]

35. Song, R.; Ponge, D.; Raabe, D.; Speer, J.G.; Matlock, D.K. Overview of processing, microstructure and mechanical properties of ultrafine grained bcc steels. Mater. Sci. Eng. A 2006, 441, 1-17. [CrossRef]

36. Park, H.W.; Yanagimoto, J. Formation process and mechanical properties of $0.2 \%$ carbon steel with bimodal microstructures subjected to heavy-reduction single-pass hot/warm compression. Mater. Sci. Eng. A 2013, 567, 29-37. [CrossRef] 
37. Park, H.W.; Shimojima, K.; Sugiyama, S.; Komine, H.; Yanagimoto, J. Microstructural evolution and formation mechanism of bimodal structure of $0.2 \%$ carbon steel subjected to the heavy-reduction controlled rolling process. Mater. Sci. Eng. A 2015, 624, 203-212. [CrossRef]

38. Dieter, G.E. Mechanical Metallurgy, 3rd ed.; McGraw-Hill: New York, NY, USA, 1986.

39. Cao, G.H.; Sun, T.Y.; Wang, C.H.; Li, X.; Liu, M.; Zhang, Z.X.; Hu, P.F.; Russell, A.M.; Schneider, R.; Gerthsen, D.; et al. Investigations of $\gamma^{\prime}, \gamma^{\prime \prime}$ and $\delta$ precipitates in heat-treated Inconel 718 alloy fabricated by selective laser melting. Mater. Charact. 2018, 136, 398-406. [CrossRef]

40. Sundararaman, M.; Mukhopadhyay, P.; Banerjee, S. Precipitation of the $\delta-\mathrm{Ni}_{3} \mathrm{Nb}$ phase in two nickel base superalloys. Metall. Mater. Trans. A 1988, 19, 453-465. [CrossRef]

41. Hall, R.C. The Metallurgy of Alloy 718. J. Basic Eng. 1967, 89, 511-516. [CrossRef]

42. Huang, K.; Logé, R.E. A review on dynamic recrystallization phenomena in metallic materials. Mater. Des. 2016, 111, 548-574. [CrossRef]

43. Park, H.W.; Yanagimoto, J. Effect of carbon content on formation of bimodal microstructure and mechanical properties of low-carbon steels subjected to heavy-reduction single-pass hot/warm deformation. Mater. Sci. Eng. A 2014, 607, 542-550. [CrossRef]

44. Lee, S.H.; Na, H.S.; Kim, B.H.; Kim, D.J.; Kang, C.Y. Effect of niobium on the ferrite continuous-cooling-transformation (CCT) curve of ultrahigh-thickness Cr-Mo steel. Metall. Mater. Trans. A 2013, 44, 2523-2532. [CrossRef] 